\title{
EMOTIONAL INTELLIGENCE: AN EMPIRICAL STUDY AMONG POST-GRADUATE STUDENTS
}

\author{
Dr. Mohammed Mansoor AP \\ Assistant Professor, GITAM School of Business, \\ GITAM-Gandhi Institute of Technology and Management University, Bengaluru, India \\ Dr. Syed Khalid Perwez \\ Professor, VIT Business School, Vellore Institute of Technology, \\ Vellore, Tamil Nadu, India.

\section{Dr. Swamy TNVR} \\ Associate Professor, VIT Business School, Vellore Institute of Technology, \\ Vellore, Tamil Nadu, India.
}

\begin{abstract}
In today's world the most important factor is to be aware of expressing and controlling our emotions, to maintain effective interpersonal relationship in workplace. So Emotional Intelligence is major factor to study in the current society. The study aim to understand the EI among post graduates students in Bengaluru. Students community are facing huge crisis on EI base factors like, self-awareness, Self-regulation, motivation, empathy and social skills. The study investigates the student's Emotional intelligence in Bengaluru. The Descriptive research design has been adopted in this study. Our target population is post graduates students in Bengaluru. The sample size is 100; we have used non probability sampling method with purposive sampling techniques, we have used survey questionnaires method to collect the primary data. The statistical analyses are used in this study like percentage analysis, $t$ test, Chi square, Correlation and regression. The results indicates that the significant relationship between Emotional Intelligence and self-management among $P G$ students.
\end{abstract}

Key words: Intelligent Quotient, Emotional Quotient (EQ), Performance, Perception.

Cite this Article: Mohammed Mansoor AP, Syed Khalid Perwez and Swamy TNVR, Emotional Intelligence: An Empirical Study among Post-Graduate Students, International Journal of Management, 11(9), 2020, pp. 227-237.

http://iaeme.com/Home/issue/IJM?Volume $=11 \&$ Issue $=9$ 


\section{INTRODUCTION}

According to George (2000) explained the role of EI through description of four aspects of Mayer \& Salovey's model (1990) in effective leadership. EI abilities should be correlated from the already existing intelligences and it must develop with age. However the relationship of EI with performance is often contradictory with the research which shows a significant relationship with other relationship between EI and the student performance. This study also helps us to find the interpersonal relationship in workplace where the postgraduate students are working under intern. It was found that EI was considered to be transformational in their managing style by their sub-ordinates and also they are more effective.

\subsection{Self-Awareness}

It is one of the important aspects in EI. Self-awareness recognizes the emotions and the impact that is there on their life. Also it is used to find the awareness of self and emotions can be developed. Self-awareness helps the human beings to get an idea according to the situation. Developing awareness of the assumptions which hold about others is an important aspect of EI. Assumptions about us can be positive or negative. Negative assumptions include thoughts such as 'Bad things always happen to me'. Positive assumptions might include thoughts such as 'If I keep trying I will be successful'. The PG level students will be aware of each and every situation they are going to face at workplace should be known and understand by their own.

\subsection{Self-Regulation}

It is the second key area of personal skill that makes up emotional intelligence. It is concerned with how you control and manage your emotions, inner resources and abilities by yourself. It is used to learn to manage emotions and reactions of an individual to improve his or her EI. Self-control can be used by a wide range of organisms and organizations, but for our purposes, we will focus on the psychological concept of self-regulation.

Self-regulation theory (SRT) simply outlines the process and the components involved when we decide what to think, feel, say and do. It monitors, influences, judge, react to our own behaviour that what we think and how we feel. This used to help the post-graduate students to control or regulate themselves.

\subsection{Motivation}

Many of us are aware of IQ (Intelligence Quotient). Higher capital IQs indicates better cognitive abilities than the lower IQ level. So motivation or self-motivation includes our personal drive to improve and achieve commitment to reach our goals. It improves overall quality of life.

According to Daniel Goleman, who developed the concept of EI in the mid'90s, identified four elements that makeup motivation, which add up to become more successful. This helps the PG level students to motivate themselves to make the work or project successful by reaching their desired goal.

\subsection{Social Skills}

Social skills and emotional intelligence refers to the skills needed to handle and influence other people's emotions effectively. This may sound like manipulation, but it can actually be as simple as understanding that and smiling at people makes them smile back, and can therefore make them feel much more positive. A communication skill plays a vital role in listening and also to convey in your own thoughts and perhaps more importantly the feelings. 


\section{LITERATURE REVIEW}

The term "emotional intelligence" felts contradiction in the area of behavioral science. In various customs and opinion has reviewed emotions as unsystematic disruption of stress action, with potentially troublemaking must be kept in restricted. According to B.C., Publilius Syrus (1961) in first century, "Rule your feelings, lest your feelings rule you. More latterly, in psychology, Young defined emotions as "acute disturbances of the soul as a whole" P. T. Young (1943), and modem introductory texts described emotion as "a disorganized response, largely visceral, resulting from the lack of an effective adjustment" L. F. Schaffer, B. Gilmer, and M. Schoen (1940). In this opinion, pure emotion is seen as having a "complete loss of intellectual control" and containing no "line of conscious purpose" P. T. Young (1936).

A secondary views emotional intelligence as an organize reaction with adaptively focuses cognitive activities and subsequent action R. W. Leeper (1948), J. A. Easterbrook (1959). Rather than characterizing emotion as chaotic, haphazard, and something to outgrow, Leeper suggested that emotions are primarily motivated forces; they are "processes which arouse, sustain, and direct activity" R. W. Leeper (1948). Modern theories of emotion also see it as directing cognitive activities adaptively G. Mandler (1975), H. A. Simon (1982).

According to Janaki S and Noor (2015) H A K "investigated the level of academic related anxieties among final year undergraduates and the relationships among the dimensions of the anxieties. The scope of this study focuses on three anxieties; library anxiety, English language anxiety and communication anxiety. Three sets of survey instruments were used; Library Anxiety Scale (LAS), Foreign Language Classroom Anxiety Scale (FLCAS), and Personal Report of Communication Apprehension (PRCA-24). It was found that all four dimensions of communication anxiety - formal, interpersonal conversations, group discussion, and public speaking - correlated with at least one or more of the five dimensions of library anxiety - barriers with staff, library services barriers, library resources barriers, affective barriers, and internet services barriers. Acknowledgment of the prevalence of these anxieties among students can help libraries and librarians to make learning in the library less stressful by focusing more on students and their problems instead of the library and its environment".

Muhammad Umar F (2014) The Taif University English Language Center (TUELC) performed an observational analysis on English language learners to find out the connection between their emotional intelligence ( EI) and language skills A group of 200 students (male and female) were randomly selected for this study, studying English at the undergraduate level. Data collected through the EI Inventory were matched to their academic achievement in English based on a four-skill assessment. The result revealed a close relationship between EI and language skills of undergraduate students at TUELC and EI also affects English language skills of the students.

Sajjad Ullah Jan et al (2016) this study focused on the students' "library anxiety" and "emotion perception," and the researcher investigated the relationship between these two concepts. In total, an analysis of 279 self-reporting questionnaires was used. The findings verified the nature of the library anxiety phenomenon, with these students becoming more nervous about factors related to "user education" and "user awareness." They exhibited greater emotional perception skills. There appeared a negative relation between library anxiety and perception of emotion. The results suggest that training programs for user education and perception of emotions should be developed to surmount.

Sajjad Ullah Jan et al (2017) Reviewed the emotional intelligence literature and its relationship with students' academic and non-academic characteristics with an emphasis on the significance of that relationship. This analysis shows that students' emotional intelligence is a crucial factor for them when coping with a stressful situation. It also shows that emotional 
intelligence can help students in managing library anxiety which leads to better academic performance. This article will help academic librarians understand the role emotional intelligence plays in patron's library related activities. This field should really be given more importance in future study.

Sajjad Ullah Jan et al (2018) Emotional intelligence has a strong relationship with anxieties in higher education. From the published literature it becomes evident that a student with high emotional intelligence will face low academic anxiety and vice versa. Likewise, library anxiety, which is an academic anxiety, often affects the academic performance of the students. Students' library anxiety can increase or decrease along with their ability to comprehend and control their own and other emotions. However, the relationship between these two principles is dearth in literature. Data were obtained from university undergraduates about these concepts. Findings developed important relationships between the participants' emotional intelligence, library anxiety, and academic performance. This research has practical consequences for academics and qualified librarians in addressing students' library anxiety and academic success.

Abbas Abdollahi et al (2013) Examined the relationship of boy students in Tehran , Iran, between emotional intelligence and depression; For this study the sample size was 188 boy students aged 16 to 19 years were picked. The findings found that there was a negative correlation between high emotional intelligence capability with depression, and a positive association between low emotional intelligence capabilities with depression. These findings showed that emotional intelligence has been a powerful predictor of adolescent depression.

Misbah Malik et al (2013) the researcher identified the relationship between emotional intelligence and test anxiety among students in Specific School System studying at the higher secondary level. The findings showed negative association between Emotional Intelligence and Test Anxiety among students (coefficient of correlation-0.603). It was advised, in the light of significant results, to use techniques to minimize test anxiety and to impact emotional intelligence.

Adil Adnan et al (2012) this study examined the connection between emotional intelligence and academic performance of the students. Nationality and gender are seen as variables for calculating the emotional intelligence gap. The results were not able to connect emotional intelligence to student academic success, while a positive association was found between the students ' emotional intelligence and age. In addition, the students' study did not find any disparity in emotional intelligence across nationality and gender.

Neda Esmaeili and Ezzatallah B J (2013) this research explores the relationship between the emotional intelligence and the mental health of high school students at Qaemshahr Islamic Azad University. Spearman correlation coefficient test results revealed a strong association between emotional intelligence and mental health for both male and female categories. Findings showed that there is a major connection between the emotional intelligence components and the mental wellbeing of mention groups (men, women, entirely).

There is a significant relationship between the EI of employees and job performance. Abstractive link between EI and performance have been provided in the past (e.g., Goleman, 1998) but clear empirical evidence has been lacking. Thus, if one accepts EI as relevant indicators for performance and positive evaluations of the service, this study will contribute towards strengthening the position of EI in the service sector like education.

The result is in conformity with that of Goleman (1998), who expressed the view that EI tends to increase as one matures and gains experience. The probable explanations for the result could be attributed to the teacher's interaction with students of diverse backgrounds their service career. This may have, led, to people-oriented approach and development of skill in the series of such self-management training and participation. This could be the reasons as 
to why teachers' position is provided to the students with emotional perception in the education sector. Studies related to EI and job performance is still in its beginning stage in Indian context. The review of literature does not find any research which has been done in Self-management to establish a relation between EI and performance among PG students, particularly in the Indian context. Thus, the current study is therefore a reflection and a step towards one of the researches that focus within the area of EI and Self-management.

\section{OBJECTIVES OF THE STUDY}

- To understand the factors of emotional intelligence among P.G students.

- To find out the relationship with these factors on emotional intelligence among PG students.

\section{RESEARCH METHODS}

In this study, the descriptive and quantitative methods has been adopted, and to find the relationship among the factors of emotional intelligence. Determinants of "emotional intelligence is Empathy, Self-awareness, Self-management, Social skills, and Selfmotivation". Identify and express feelings and emotions towards personnel and professional life, with Problem solving and decision making towards leadership. The simple random sampling has been implemented, framing of nationalize and private banks in two sets, and unit selection will be randomized. The present research was analyzed using different statistical methods such as factor analysis, step-wise regression and structural equation model

\section{DATA ANALYSIS AND INTERPRETATION}

The table-1 shows that the loading factors in SPSS like adaptability, social skills, emotional perception, assertiveness, self-management and stress management all the significant values as been shown in rotated component matrices for item reduction.

Table 1 Factor Analysis

\begin{tabular}{|l|c|c|c|c|c|}
\hline \multicolumn{1}{|c|}{ Factors/Items } & $\mathbf{1}$ & $\mathbf{2}$ & $\mathbf{3}$ & $\mathbf{4}$ & $\mathbf{5}$ \\
\hline Adaptability & 0.841 & 0.817 & 0.714 & 0.677 & 0.577 \\
\hline Social skills & 0.847 & 0.795 & 0.750 & 0.711 & 0.566 \\
\hline Emotional Perception & 0.860 & 0.718 & 0.522 & - & - \\
\hline Assertiveness & 0.811 & 0.546 & 0.519 & - & - \\
\hline Self-Management & 0.549 & 0.773 & 0.752 & 0.684 & - \\
\hline Stress management & 0.522 & 0.843 & 0.656 & - & - \\
\hline
\end{tabular}

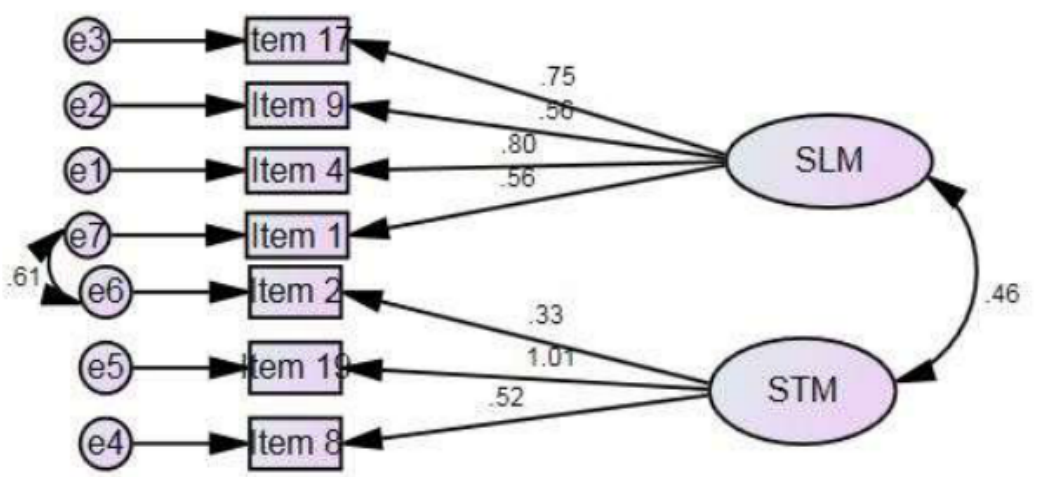

Figure 1 Confirmatory Factor Analysis 
The above figure shows the standardized co-efficient for self-management and stress management are $.75, .56, .80, .56$ and $.33,1.01, .52$ it shows the validity of the scale.

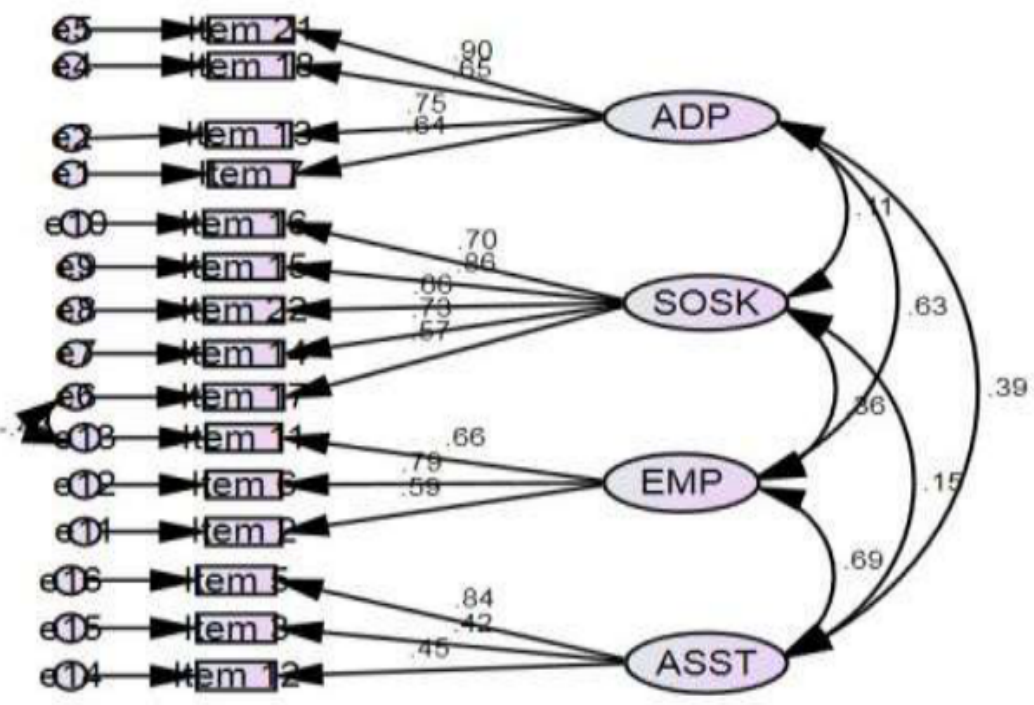

Figure 2

The above figure shows the standardized co-efficient for Adaptability, social skills, Emotional perception and Assertiveness are .90, .65, .75, .64, .70, .86, .66, .73, .57, .66, .79, $59 .$, and $.84, .42, .45$. It shows the validity of the scale.

Table 2 Model fit among the factor

\begin{tabular}{|l|c|c|c|c|c|}
\hline \multicolumn{1}{|c|}{ Factors/ Model fit } & GFI & AGFI & CFI & RMSEA & PCLOSE \\
\hline $\begin{array}{l}\text { Mediating and Dependent } \\
\text { factors }\end{array}$ & 0.889 & 0.741 & 0.890 & 0.141 & 0.057 \\
\hline Independent factors & 0.812 & 0.727 & 0.917 & 0.070 & 0.246 \\
\hline
\end{tabular}

The table- 2 shows that the model fit among the factor like Adaptability, Social skills, Emotional perception, Assertiveness, stress management and self-management. Hence its proved that the Goodness of fit will be 0.889 and 0.812 and Average goodness and common fit will be also above 0.70 it shows that there is a valid scale to measure the this factors towards emotional intelligence.

Effect of assertiveness, emotional perception, Social skills and Adaptability on Selfmanagement among PG students

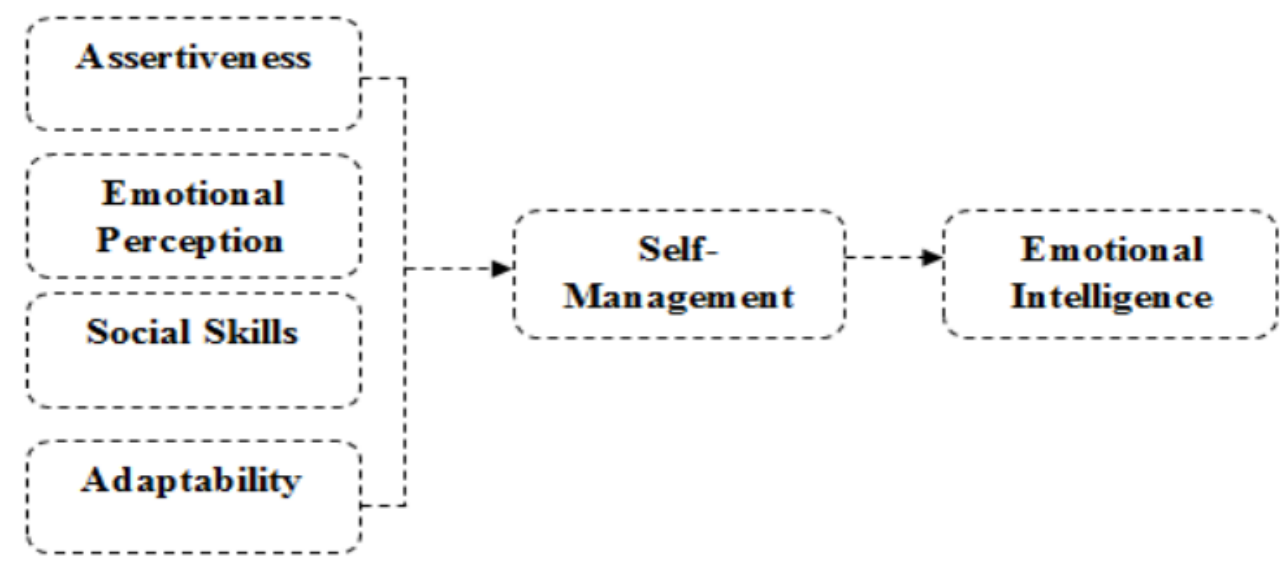

Figure 3 Conceptual Frame work 
Table 3

\begin{tabular}{|l|l|c|c|c|}
\hline \multicolumn{1}{|c|}{ Item (X) } & \multicolumn{1}{c|}{ Item (Y) } & R value (Beta) & T value & P value \\
\hline Assertiveness & Self-Management & 0.02 & .150 & 0.88 \\
\hline $\begin{array}{l}\text { Emotional } \\
\text { Perception }\end{array}$ & Self-Management & 0.25 & 1.757 & 0.08 \\
\hline Social skills & Self-Management & 0.55 & 4.405 & $0.00^{* *}$ \\
\hline Adaptability & Self-Management & 0.32 & 2.257 & $0.02^{*}$ \\
\hline
\end{tabular}

The table no 3 shows that the effect of social skill, Adaptability, Assertiveness and emotional perception on self-management, the social skill and adaptability have $55 \%$ and $32 \%$ since the $\mathrm{p}$ value is less than 0.05 hence it proves that the significant relationship between self-management among PG students, and rest of the other factors assertiveness and emotional perception has $2 \%$ and $25 \%$ effect on self-management and it shows the relationship without significance.

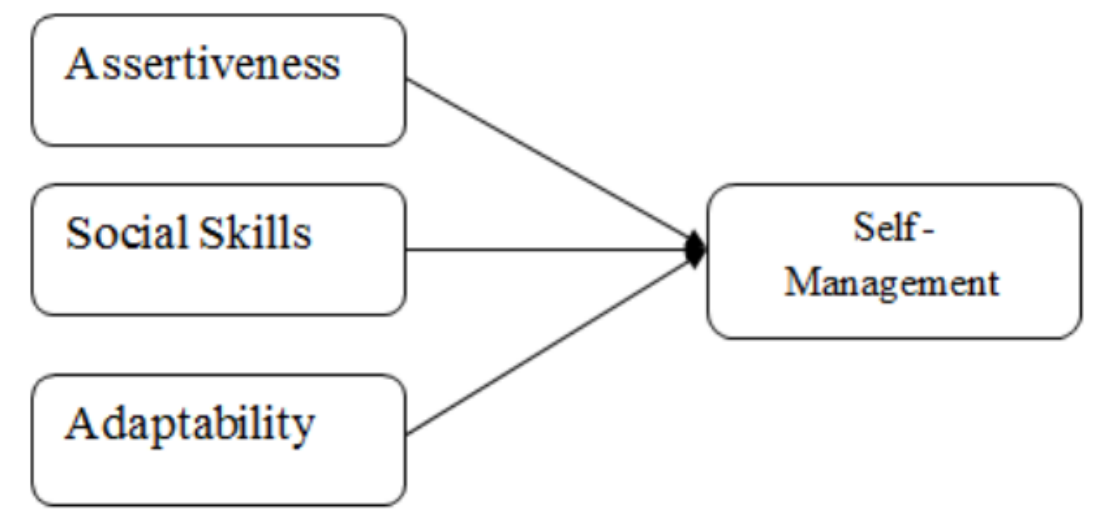

Figure 4

Table 4 Effect on Self-management

\begin{tabular}{|l|c|c|c|c|}
\hline \multicolumn{1}{|c|}{ Factors } & R value & Se (c) & t value & P value \\
\hline Adaptability & \multirow{3}{*}{0.640} & 0.396 & 2.813 & \multirow{2}{*}{$0.00^{* *}$} \\
\cline { 1 - 2 } Social skills & 0.526 & 4.473 & \\
\cline { 1 - 3 } & & 0.226 & 1.609 & \\
\hline Assertiveness & & & \\
\hline
\end{tabular}

The independent factors like adaptability, social skills and assertiveness had direct significant effect on self-management. The table shows that the $R$ value is 0.640 , and $p$ value is less than $1 \%$ level of significance it means that overall $64 \%$ will be correlated with selfmanagement.

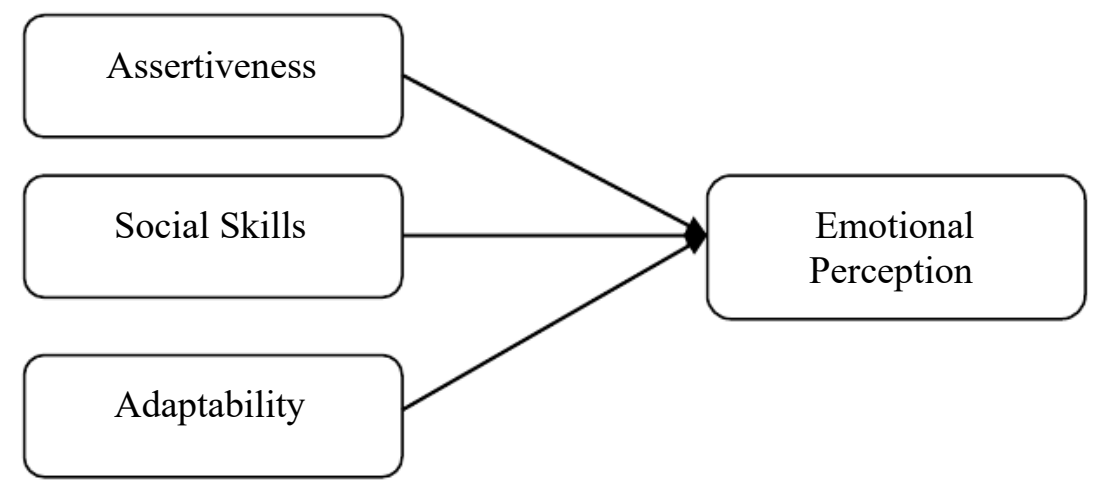

Figure 5 
Emotional Intelligence: An Empirical Study among Post-Graduate Students

Table 5 Effect on Emotional Perception

\begin{tabular}{|c|c|c|c|c|}
\hline Factors & R value & Se (c) & t value & P value \\
\hline Adaptability & \multirow{3}{*}{0.518} & 0.346 & 2.209 & \multirow{3}{*}{$0.004 *$} \\
\hline Social skills & & 0.135 & 1.029 & \\
\hline Assertiveness & & 0.203 & 1.297 & \\
\hline
\end{tabular}

The independent factors like adaptability, social skills and assertiveness had direct significant effect on emotional perception. The table shows that the $\mathrm{R}$ value is 0.518 , and $\mathrm{p}$ value is less than $5 \%$ level of significance it means that overall $52 \%$ will be correlated with emotional perception.

\section{RESULTS AND DISCUSSIONS}

In developed countries, emotional intelligence is an entrenched concept, but in India it has gained in importance late. The present study aims to show the attitude of students in the banking sector towards this extremely significant term. The study identified that majority of the respondents $(80 \%)$ were not aware the concept of emotional intelligence and only few $(20 \%)$ were ignorant about the same. This clearly shows that the PG students are no exception, since most employees were aware of the popularly used concept known as EI.

This study indicates that the model fits into variables such as adaptability, cognitive skills, emotional intelligence, assertiveness, stress control, and self-management. It is also shown that the goodness of fit will be 0.889 and 0.812 and that the average goodness and general fit will also be above 0.70 which shows that there is a reliable scale to calculate the emotional intelligence of these variables.

This study shows that the impact of social skills, adaptability, assertiveness and emotional perception on self-management, social skills and adaptability becomes $55 \%$ and $32 \%$ since the $\mathrm{p}$ value is less than 0.05 hence indicates that the significant relationship between selfmanagement among PG students and the rest of the other factors is $2 \%$ on self-management and it shows the relationship without significance. The independent factors such as adaptability, social skills and assertiveness directly affected self-management. The table indicates that the $\mathrm{R}$ value is 0.640 , and the $\mathrm{p}$ value is less than 1 per cent meaning point, which means that 64 per cent would be associated with self-management overall. Specific variables such as adaptability, social skills and assertiveness have had a clear impact on selfmanagement. The study indicates that the $R$ value is 0.640 , and the $p$ value is less than 1 per cent meaning point, which means that 64 per cent would be associated with self-management overall. The independent factors such as adaptability, social skills and assertiveness directly affected emotional perception. It indicates that the $\mathrm{R}$ value is 0.518 , and the $\mathrm{p}$ value is less than 5 per cent meaning point, indicating that 52 per cent would be associated with emotional experience overall

\section{CONCLUSION}

This study empirically investigates the relationship between self-management and emotional intelligence in the students. There are two objectives of the study: first is to determine if EI and educational performance has significant relationship; second is to demonstrate which aspect of self-management is a major contributor towards performance and third is to see if assertiveness, emotional perception, Social skills and Adaptability on Self-management are predictive of EI. All the three factors of EI, i.e., assertiveness, emotional perception, and selfmanagement, have been found to contribute towards student's satisfaction but emotional maturity has been identified as the dominant factor responsible for performance in the present study. The finding further shows that working experience in service counters can predict EI. 
The fact that EI is significantly related to educational satisfaction may have valuable implications for the development of students. By evaluating one's level of EI, necessary areas for improvement of PG students might be identified. Correspondingly, in the student, trainers might identify tough, flaw and gaps that can be useful in both training and Self-management. Therefore, they need to develop the self-management as a part of their EI particularly empathy, social skills and emotional perception. As EI has become very critical to the success, the attributes of EI should be recognized globally and become inclusive of every curriculum and training plan. As the study reveals EI can be learnt and escalate with experience, the experience can be certified during placement and selection process.

\section{FUTURE RESEARCH AND ITS IMPLICATIONS}

Emotional intelligence can provide a basis for personality organization; it can also propose a model for personality researchers exploring emotion. Investigator may wish to analyze emotions within themselves, evaluating the emotions of others, how emotions are controlled, or the adaptive uses of emotion. Additionally, however, some can prefer a research approach that involves recognizing emotionally intelligent individuals by using laboratory tasks or traditional scales. Students may also look to learn emotionally intelligent skills and strategies to encourage them. We would also hope that studies in this area could analyze the role that emotional intelligence plays in understanding other complex social processes, such as friendship formation and other close relationships. Finally, by recognizing the importance of emotional intelligence to a balanced personality and how it can be promoted. We can come to recognize advantageous qualities or appropriate changes in social and cultural institutions.

\section{REFERENCES}

[1] Mayer, J. D., \& Geher, G. (1996). Emotional intelligence and the identification of emotion. Intelligence, 22(2), 89-113.

[2] Schutte, N. S., Malouff, J. M., Hall, L. E., Haggerty, D. J., Cooper, J. T., Golden, C. J., \& Dornheim, L. (1998). Development and validation of a measure of emotional intelligence. Personality and individual differences, 25(2), 167-177.

[3] Salovey, P., \& Mayer, J. D. (1990). Emotional intelligence. Imagination, cognition and personality, 9(3), 185-211.

[4] Mayer, J. D., Caruso, D. R., \& Salovey, P. (1999). Emotional intelligence meets traditional standards for an intelligence. Intelligence, 27(4), 267-298.

[5] Mayer, J. D., Salovey, P., Caruso, D. R., \& Sitarenios, G. (2001). Emotional intelligence as a standard intelligence.

[6] Cavallo, K., \& Brienza, D. (2006). Emotional competence and leadership excellence at Johnson \& Johnson. Europe's Journal of Psychology, 2(1).

[7] Boyatzis, R. E., Goleman, D., \& Rhee, K. (2000). Clustering competence in emotional intelligence: Insights from the Emotional Competence Inventory (ECI). Handbook of emotional intelligence, 343-362.

[8] Publilius Syrus, Sententiae, in Minor Latin Poetf, J. W. Duff and A. M. Duff (eds.), Harvard University Press, Cambridge, c. 100 BC/1961.

[9] P. T. Young, Emotion in Man and Animal: Its Nature and Relation to Attitude and Motive, John Wiley and Sons, New York, 1943. p. 263

[10] L. F. Schaffer, B. Gilmer, and M. Schoen, Plychology, Harper \&. Brothers, New York. pp. xii, 521,1940. p. 505

[11] P. T. Young, Motivation of Behavior, John Wiley \& Sons, New York, 1936. pA57 -458 
[12] R. S. Woodworth, PJ'ychology, 4th Edition. Henry Holt, New York, 1940.

[13] R. W. Leeper, A Motivational Theory of Emotions to Replace "Emotions as Disorganized Response," Psychological Review. 55. pp. 5-21, 1948. p. 17

[14] J. A. Easterbrook, The Effects of Emotion on Cue Utilization and the Organization of Behavior, Psychological Review, 66. pp. 183-200, 1959.

[15] G. Mandler, Mind and Emotion, Wiley, New York, 1975.

[16] H. A. Simon, Comments, in Affect and Cognition, M. S. Clark and S. T. Fiske (eds.), Erlbaum, Hillsdale, New Jersey, pp. 333-342, 1982.

[17] J. D. Mayer, How Mood Influences Cognition, in Advances in Cognitive Science, Volume I, N. E. Sharkey (ed.), Ellis Horwood, Chichester, pp. 290-314,1986.

[18] A. Sloman and M. Crocher, Why Robots Will Have Emotions, in Proceedings of the Seventh International Joint Conference on Artificial Intelligence. Volume I, A. Drinan (ed.), Vancouver, 1981.

[19] C. E. Izard and S. Buechler, Aspects of Consciousness and Personality in Terms of Differential Emotions Theory, in Emotion: Theory. Research. And Experience, Volume I, R. Plutchik and H. Kellerman (eds.), Academic Press, New York, pp. 165-187, 1980.

[20] S. S. Tomkins, Affect, Imagery, and Consciousness, Vol. 1: The Positive Affects, Springer, New York, 1962.

[21] R. L. Thorndike and S. Stein, An Evaluation of the Attempts to Measure Social Intelligence, Psychological Bulletin. 34. pp. 275-284, 1937.

[22] R. E. Walker and J. M. Foley, Social Intelligence: Its History and Measurement, Psychological Reports. 33, pp. 839-864. 1973.

[23] E. L. Thorndike, Intelligence and Its Uses, Harper's Magazine, 140. pp. 227-235,1920.

[24] E. A. Weinstein, The Development of Interpersonal Competence, in Handbook of Socialization Theory and Research, D. A. Goslin (ed.), Rand McNally, Chicalo, 1969.

[25] Bureau of Personnel Administration, Partially Standardized Tests of Social Intelligence, Public Personnel Studies, 8, pp. 73-79, 1930.

[26] R. A. Dienstbier, The Role of Emotion in Moral Socialization, in Emotions, Cognition, and Behavior. C. E. Izard, J. Kagan, and R. B. Zajonc (eds.), Cambridge University Press, Cambridge, pp. 484-514,1984.

[27] M. L. Hoffman, Interaction of Affect and Cognition in Empathy, in Emotions, Cognition, and Behavior, C. E. Izard. J. Kagan, and R. B. Zajonc (eds.), Cambridge University Press, Cam,bridge, pp. 103-131, 1984.

[28] H. Gardner, Frames of Mind, Basic Books, New York, 1983.

[29] S. Epstein, Controversial Issues in Emotion Theory, in Review of Personality and Social Psychology: Emotions. Relationship and Health, P. Shaver (ed.), Sage Publications, Beverly Hills, pp. 64-88, 1984.

[30] Jan, S. U., Anwar, M. A., \&Warraich, N. F. (2017). Emotional intelligence and academic anxieties: A literature review. New Review of Academic Librarianship, 23(1), 6-17.

[31] Karim, J. (2011). Emotional intelligence: A cross-cultural psychometric analysis (Doctoral dissertation, Aix-Marseille 3).

[32] Jan, S. U., Anwar, M. A., \&Warraich, N. F. (2016). Library anxiety and emotion perception among the undergraduate social sciences students: A relationship study. Behavioral\& Social Sciences Librarian, 35(2), 52-63. 
[33] Farooq, M. U. (2014). Emotional intelligence and language competence: a case study of the English language learners at Taif University English language centre. Studies in Literature and Language, 8(1), 6.

[34] Jan, S. U., \& Anwar, M. A. (2018). Emotions management skills and barriers with library staff: A correlational survey of agriculture students. The Journal of Academic Librarianship, 44(1), 33-38.

[35] de Jager, K., Nassimbeni, M., Daniels, W., \& D'Angelo, A. (2018). The use of academic libraries in turbulent times: student library behaviour and academic performance at the University of Cape Town. Performance Measurement and Metrics, 19(1), 40-52.

[36] Doris, K. A., Provata, P. A., \&Vraimaki, E. (2017). Assessing library anxiety in undergraduate students using the Greek Library Anxiety Scale (G-LAS). In Strategic Innovative Marketing (pp. 675-682). Springer, Cham.

[37] Sinnasamy, J., \& Karim, N. H. A. (2017). Academic related anxieties: A case study investigating the relationships among library, communication and language anxieties among non-native speakers of English. Malaysian Journal of Library \& Information Science, 20(2).

[38] SeyyedHosseini, S., Khosravi, A., \&BasirianJahromi, R. (2014). Investigating the relationship between library anxiety and emotional intelligence. Webology, 11(2).

[39] Adnan, A., Chaudhry, A., \& Malik, M. I. (2012). Emotional intelligence and students' academic performance: A study conducted in Pakistan and Afghanistan. Science Series Data Report, 4(3), 61-69.

[40] Malik, M., Akhter, M., Fatima, G., \&Safder, M. (2013). Emotional intelligence and test anxiety: A case study of unique school system. Journal of Elementary Education, 23(2), 4956.

[41] Bai, S. (2011). Study of Anxiety proneness and emotional intelligence in relation to academic achievement of pre-university students. International Referred Research Journal, 2(22), 1-5.

[42] Matteson, M. L., \& Farooq, O. (2013). Feeling our way: Emotional intelligence and information literacy competency.

[43] Motalebi, S. A. (2013). Examining the association between emotional Intelligence with depression among Iranian boy students. Examining the Association between Emotional Intelligence with Depression among Iranian Boy Students.

[44] Jan, S. U., Anwar, M. A., \&Warraich, N. F. (2018). The relationship between emotional intelligence, library anxiety, and academic achievement among the university students. Journal of Librarianship and Information Science, 0961000618790629.

[45] Zare, H., \& Nouri, Z. (2013). An assessment of the relationship between emotional intelligence and computer anxiety among university students of Payame Noor University. Reef Resources Assessment and Management Technical Paper, 38(5), 325-330. 